JEAN JEAN. M • Muralismo y memorias en América Latina: el caso del mural comunitario y colaborativo sobre la masacre de Panzós en Guatemala

\title{
Muralismo y memorias en América Latina: el caso del mural comunitario y colaborativo sobre la masacre de Panzós en Guatemala ${ }^{1}$
}

Muralism and memories in Latin America: the case of the community and collaborative mural on the Panzós massacre in Guatemala

Melina Jean Jean

UNIVERSIDAD NACIONAL DE LA PLATA ${ }^{2}$

Resumen. El contexto de guerra fría se articuló en torno a la confrontación entre Estados Unidos y la Unión Soviética. Es en este escenario que se originó la masacre de Panzós, la cual se inscribe en la sangrienta historia reciente de Guatemala a mediados del siglo XX. Considerando este contexto histórico, el presente artículo tiene como objetivo identificar la práctica artística vinculada a los procesos de memorias de hechos traumáticos del pasado reciente, caso de estudio "Mural masacre de Panzós en Guatemala". Para ello se tuvieron en cuenta los relatos de artistas y docentes de la Escuela de Arte y Taller Abierto de Perquín, El Salvador, quienes fueron convocadas desde Guatemala por el Equipo de Estudios Comunitarios y Acción Psicosocial (ECAP). La particularidad de esta obra artística radica en sus hacedores/as. Se trata de integrantes de la comunidad de mayas-q'eqchíes víctimas de la masacre. Los resultados señalan que las y los participantes del mural, generan una narración plástica visual que materializa las memorias no solo de la masacre, sino de la historia de Panzós. En este trabajo se concluye que la práctica artística, no solo es una representación de episodios, sino que el arte puede colaborar en las elaboraciones de experiencias traumáticas de las y los individuos.

Palabras Clave: Mural; Memoria Colectiva; Panzós; Guatemala; Práctica Artística.

\begin{abstract}
The context of the cold war was articulated around the confrontation between the United States and the Soviet Union. It is in this scenario that the Panzós massacre originated, which is part of the bloody recent history of Guatemala in the mid-20th century. Considering this historical context, this article aims to identify the artistic practice linked to the memory processes of traumatic events of the recent past, case study "Mural massacre of Panzós in Guatemala". To do this, consider the stories of artists and teachers at the Perquín School of Art and Open Workshop, El Salvador, who were convened from Guatemala by the Community Studies and Psychosocial Action Team (ECAP). The particularity of this artistic work lies in its makers. They are members of the MayanQ'eqchí community who were victims of the massacre. The results indicate that the participants in the mural involve a visual plastic narration that materializes the memories not only of the massacre, but of the history of Panzós. This work concludes that artistic practice is not only a representation of episodes, but that art can collaborate in the traumatic experiences of individuals.
\end{abstract}

Key Words: Mural; Collective Memory; Panzós; Guatemala; Artistic Practice

\footnotetext{
${ }^{1}$ Investigación financiada en el marco de la beca doctoral del Consejo Nacional de Investigaciones Científicas y Técnicas (CONICET) Instituto de Investigaciones en Humanidades y Ciencias Sociales (IdIHCS), Universidad Nacional de La Plata .

${ }^{2}$ Licenciada y Profesora en Historia del Arte por la Facultad de Artes (FA), Universidad Nacional de La Plata (UNLP). Magister en Historia y Memoria por la Facultad de Humanidades y Ciencias de la Educación (FaHCE, UNLP). Doctoranda en Historia (FaHCE) en el Instituto de Investigaciones en Humanidades y Ciencias Sociales (UNLPCONICET).
} 


\section{Introducción}

La elaboración y representación de los pasados violentos de nuestros pueblos latinoamericanos ha sido abordada de diversas formas que se ajustan a las lógicas y posibilidades del presente, y que guardan estrecha relación con los procesos de búsqueda de verdad, justicia y especialmente de construcción colectiva de memorias. Algunas de las dificultades radican en que se trata de eventos de alcances traumáticos en los que las sociedades fueron sometidas a terrorismos, dictaduras, y todo tipo de violencias de Estado que perpetraron un sinfín de violaciones a los derechos humanos como masacres, genocidios, represiones, asesinatos, desapariciones, desplazamientos forzados, exilios, refugios, entre otras. Las prácticas de memoria se inscriben de esta forma en el afán de no olvidar estos hechos, de recordarlos para no repetir, y ejemplarizar para las generaciones presentes y futuras. La construcción de memoria colectiva entonces, no solo permite la elaboración de pasados recientes, también permite ejercer la práctica de reconocimiento de aquello que aún en el presente se considera no ha sido resuelto. Nos referimos a lo que Rousso (2018) definió como aquellos pasados que no pasan. Ya sea porque la lucha por la verdad y la justicia no ha cesado y el trabajo con las memorias se convierte en un imperativo, como también por las condiciones actuales de violencias en democracias y la necesidad de continuar el camino para conquistar derechos.

Frecuentemente estas prácticas de memorias recurren a los lenguajes artísticos por las posibilidades que el arte ofrece para trabajar sobre pasados violentos y experiencias traumáticas. Nos referimos a experiencias de sometimiento al terror ejercido y el horror vivido, donde las palabras y las conceptualizaciones muchas veces resultan insuficientes para aquello que reclama ser contado, conocido, representado y recordado. Tal es el caso que aquí presentamos: la masacre de Panzós en 1978 se hizo memoria colectiva a través de un ejercicio artístico-plástico en el año 2010, cuando la comunidad guatemalteca de mayas-q'eqchíes diseñó y pintó un mural que representa los acontecimientos de esta tragedia que se resiste a ser olvidada. No solo por los y las sobrevivientes sino también por sus familias, y aquellos/as jóvenes nacidos/as después, quienes heredaron estas memorias compartidas y asumidas como propias, tanto por el pasado de origen común como fundamentalmente por lo sentido y vivido desde el presente. En este trabajo reponemos el proceso de construcción del mural para conocer y reflexionar su dimensión como práctica social de memoria colectiva, no solo en su aporte a la reconstrucción de los hechos de la masacre sino de la historia reciente de Panzós y Guatemala. Y fundamentalmente en las posibilidades que brindó en sus hacedores/as de elaborar la experiencia traumática a través de la participación activa, comunitaria, y en la puesta en marcha de sus propios recuerdos, deseos y necesidades del presente.

Como ya se anticipó, la Masacre de Panzós se inscribe en una larga tradición de violencias en Guatemala que nos conduce a pensarla en perspectiva histórica para comprenderla en los hechos y en sus memorias. Es así que debemos situarnos brevemente en el mundo de posguerra, a mitad del siglo XX y en el contexto de la Guerra Fría, en donde tuvo lugar la confrontación entre las dos superpotencias vencedoras de la segunda guerra mundial, Estados Unidos (capitalismo) y la Unión Soviética (comunismo) que configuraron un nuevo orden mundial, reorganizando el sistema internacional y definiendo las relaciones entre los Estados durante casi toda la segunda mitad del 
JEAN JEAN. M • Muralismo y memorias en América Latina: el caso del mural comunitario y colaborativo sobre la masacre de Panzós en Guatemala

siglo dando paso a mundo bipolar (Hobsbawm, 1995). Dentro del denominado "tercer mundo", América Latina constituyó una región particular. Como señala Halperín Donghi (2005), América Latina como región no abandonaría su condición de dependencia en relación a los países hegemónicos, y en este escenario de Guerra Fría sufrirá profundas transformaciones políticas, económicas, sociales y culturales, particularmente a partir de los vínculos y la injerencia de los Estados Unidos. Este país consideró que en la región la "amenaza comunista" sea hacía cada vez más visible sobre todo a partir del triunfo de la Revolución Cubana en 1959. Para ello elaboró su propia estrategia represiva conocida como Doctrina de Seguridad Nacional (DSN) una respuesta de carácter militarista que consistió en un conjunto de iniciativas políticas, sociales, económicas y, fundamentalmente, ideológicas, fundamentada en el concepto de "guerra interna" como respuesta al peligro de la "invasión" comunista.

Por otro lado, siguiendo a Grandin (2007) América Latina se encontraba transitando un proceso democratizador particular que no se adecuaba a las formas de las democracias liberales, sino a formas de "democracia social": "democracia socializada" y "socialismo democrático" (9) que llevaron a través de "partidos reformistas populares" a incorporar a grandes masas de población, más específicamente de clase obrera, en la vida política, y mejoras sociales y económicas para los sectores más pobres. Esta unión, dice Grandin "produjo una poderosa amenaza para el poder y los privilegios del orden establecido" (9) y fueron leídas en el marco de la Guerra Fría como antesalas o facilitadores del comunismo. Un caso de gran importancia para la región, es el de la "Revolución de Octubre" de 1944 iniciada en Guatemala, la cual "fue una de las estrellas más brillante del extenso aunque frágil firmamento democrático" de América Latina (6). Con esto, diez años más tarde, en 1954 este país centroamericano fue el elegido para la primera intervención latinoamericana de Estados Unidos en la Guerra Fría. Una operación total, encubierta, en la que derrocaron a Jacobo Arbenz, y en la que intervino especialmente la CIA: afirma Grandin "en ella se empleó casi cada faceta del poder estadounidense -político, económico, cultural, diplomático, militar, psicológico- y llegaría a servir como modelo para futuras acciones" (318-319). En términos generales, el caso guatemalteco puede considerarse paradigmático dentro de Latinoamérica pues padecieron décadas de políticas "antisubversivas" en los que las cifras de la Comisión de Verdad de Guatemala y la Comisión por el Esclarecimiento Histórico (CEH) son estremecedoras: de una población de aproximadamente once millones de personas 45.000 fueron desaparecidas y 200.000 muertas, de las cuales el 83,30\% fueron indígenas (en su mayoría mayas), se llevaron a cabo 600 masacres, se destruyeron 400 aldeas, y un millón de personas fueron desplazadas (Rostica 137).

\section{Guatemala en la guerra fría. La Masacre de Panzós}

El municipio de Panzós se ubica en el Valle del Río Polochic y pertenece al departamento de Alta Verapaz. Se encuentra a $275 \mathrm{~km}$ al nordeste de la capital de Guatemala, y a $127 \mathrm{~km}$ de la cabecera departamental, Cobán. Limita al norte con Senahú, Alta Verapaz; al este con El Estor, Izabal; al sur con Río Hondo, Zacapa y Purulhá, Baja Verapaz; al Oeste con la Tinta, Alta Verapaz, Purulhá y Salamá, Baja Verapaz. En la mañana del día 29 de mayo de 1978, marcharon hacia la 
cabecera municipal entre 500 y 700 hombres, mujeres y niños mayas-q'eqchíes en su mayoría miembros del Partido Comunista. Se concentraron en la plaza a la espera de ser recibidos por el alcalde, a quien le entregarían una carta que anunciaba la visita en el mes de junio, de la Federación Autónoma Sindical de Guatemala (FASGUA). El tema a tratar era el reclamo por las tierras y las quejas de los campesinos contra el accionar de los finqueros locales. El destacamento militar instalado en la plaza desde tres días antes abrió fuego sobre la multitud. Los disparos fueron hechos por las armas de reglamento que portaban los militares y las tres metralletas ubicadas en los perímetros de la plaza. Los resultados y representaciones de la masacre fueron ampliamente disputados entre los sobrevivientes y el Estado a través de comunicados oficiales y de la prensa (Grandin 258-267; Sanford 65-88). Según los sobrevivientes, hubo más de 100 muertos/as, no solo en la plaza, sino en la huida hacia a las montañas o ahogados en el río Polochic, mientras que la versión oficial solo habla de 34-35 muertos/as, los cuales fueron cargados en un camión esa misma tarde y arrojados en una fosa común en las afueras del cementerio local ${ }^{3}$. El Ejército -con el apoyo del gobierno-sostuvo que actuó en legítima defensa tras las agresiones de los q'eqchíes y acusó al Ejército Guerrillero de los Pobres, a Fidel Castro y a la Iglesia Católica. Los sobrevivientes, sin negar la portación de machetes, así como el clima de molestia y agitación, negaron rotundamente haber provocado a los soldados, más aún insisten en que la masacre fue premeditada. Siguiendo a Grandin (2007), se puede decir que los motivos sobran para sostener esta hipótesis de la premeditación. Sin embargo, además, dice el autor que en la mayoría de las representaciones de la masacre:

Se muestra a pacíficos q'eqchíes que se reúnen humildemente para solicitar reparación por injusticias históricas, tan sólo para encontrar una agresiva respuesta del Ejército. Debe hacerse una narración más completa del evento, no sólo para restaurar la agencia política (...) sino para tratar de mostrar lo que había en jugo en el conflicto y lo que la represión destruyó (237).

En este sentido, la masacre de Panzós no fue un hecho aislado sucedido en un lugar remoto de un país pequeño. Esta masacre se inscribe en un entramado mucho mayor y complejo, como lo es la Guerra Fría, y constituye un símbolo del poder en América Latina, en tanto que unificó múltiples experiencias y conflictos individuales, nacionales e internacionales, que se venían desarrollando desde mucho tiempo atrás. Nos referimos al trascurso de casi un siglo de guerra civil en Guatemala que sirvió como escenario preparatorio de la Guerra Fría en la región. Ya anticipamos la operación que en 1954 derrocó a Jacobo Arbenz y cerró -aunque no totalmente-el período revolucionario iniciado en 1944 de importantes reformas sin precedentes ${ }^{4}$. Esta primera intervención de los Estados Unidos ensayada en Guatemala evidenció la puesta en práctica de la DSN. A lo largo de las siguientes tres décadas, Estados Unidos continuaría proporcionando a las

${ }^{3}$ La fosa fue exhumada en el año 1997 por antropólogos de la Fundación de Antropología Forense de Guatemala tras el pedido de la Asociación de Familiares Detenidos Desaparecidos de Guatemala (FAMDEGUA). Los restos fueron dignamente enterrados el 29 de mayo de 1998, 20 años después de la masacre. Recuperado de: http://cpr-urbana.blogspot.com.ar/2013/05/panzos-una-historia-de-despojo-35anos.html.

${ }^{4}$ Sobre la reforma agraria y su final, véase: Grandin, 2007, 87-97. 
JEAN JEAN. M • Muralismo y memorias en América Latina: el caso del mural comunitario y colaborativo sobre la masacre de Panzós en Guatemala

fuerzas de seguridad guatemaltecas dotaciones de equipo, entrenamiento y financiamiento. Pero no solo el Ejército especializado sería un actor fundamental en la defensa ante la supuesta amenaza comunista. La operación contra Arbenz, de acuerdo con Grandin, no fue dirigida por la oligarquía, el Ejército o la Iglesia, sino por jóvenes estudiantes anticomunistas militantes, muchos de los cuales eran hijos de finqueros rurales de mediano nivel, que vivían en la ciudad:

Estos lograron generar entre la clase media, obreros, campesinos, hombres y mujeres un autoritarismo popular anticomunista diseñado tanto para mitigar la inseguridad que provocaba la liberalización de la sociedad como para contrarrestar las expectativas de consumación que anticipaba la izquierda (16).

Por otro lado, la guerra civil en Guatemala se peleó en las zonas rurales para establecer derechos de tierras, terminar con el trabajo forzado y asegurar "la simple habilidad para sobrevivir" (237). Pero, dice Grandin, "tal vez la lucha más amarga fue por el papel del Estado en la sociedad, las definiciones de ciudadanía y los límites de la participación política" (237) y en Panzós esta lucha alcanzó niveles febriles. Es a partir de esto que el autor sostiene que la masacre de Panzós, además de prefigurar las formas de violencia más mortales que le sucedieron, fue diferente a otros cientos de protestas indígenas, "en tanto que representa el final de un tipo de protesta que apelaba a demandar y exigir al Estado un control sobre el abuso de las elites locales" (1). Cuando estas se veían confrontadas públicamente, los militares, que hacían de protectores (cuando no las propias elites), "reaccionaban excesivamente, abriendo fuego sobre la reunión y conjurando el motín que durante largo tiempo habían temido" (3), tal como ocurrió en 1865 en otra masacre a mayas q'eqchíes en la plaza San Pedro Carchá, la cual además condujo a la creación del municipio de Panzós tras acelerarse el proceso migratorio que ya estaba en marcha en el Valle del Polochic. Los activistas mayas q'eqchíes:

Cultivaron su sentido de comprensión de sí mismos en una lucha por un mundo más justo (...) la frustración y posterior destrucción de sus ideales afectó no sólo a quienes sobrevivieron sino a una historia más amplia, posterior a la Segunda Guerra Mundial (...) Lo que dio a esa lucha su fuerza trascendental fue la politización e internacionalización de la vida diaria y los encuentros familiares. La política adoptó una inmanencia sorprendente, manifestándose en los reinos interiores de la sexualidad, la fe, la ética y el exilio (Grandin 26-7).

Es decir, el activismo de los q'eqchíes subrayó el poder formativo de la política para moldear las expectativas humanas. Para el autor, esto debería ser un elemento central para cualquier definición de la Guerra Fría, en tanto que no se trató solo de un evento o una causa, sino también 
de la fase intensificada de una guerra civil internacional entre distintas visiones de la forma que debía tomar esa ciudadanía social.

Desde finales del siglo XIX, a partir de la década del sesenta, la región de Panzós fue el destino de emigración de q'eqchíes de las tierras de Alta Verapaz que escapaban de las exigencias laborales y tributarias del Estado centralizado y la economía cafetalera en expansión. A partir de la reforma liberal de 1871, la región sufrió un proceso de despojo agrario, pues la reforma actualizó y reforzó la institución colonial de la servidumbre agraria. Se trató de un proceso acelerado de adjudicación de tierras que promovió cambios a favor de los agricultores alemanes (quienes controlaban, local y regionalmente el gobierno de los departamentos en donde estaban localizados y usaban el poder local para incidir en el gobierno nacional), expropiando a las comunidades indígenas con el objeto de apoyar la exportación del café (Sanford 25-7). En las primeras décadas del siglo XX, Panzós era un puerto fluvial consolidado. Casi todas las exportaciones de café pasaban por allí. Operaban también la Compañía Alemana de Ferrocarriles de Alta Verapaz y la United Fruit bajo el nombre de Polochic Banana Company; a esto se sumaba una nueva ola migratoria de empresarios dirigidos por ladinos de ascendencia alemana y con pretensiones de finqueros, en la que se encontraba la familia de Flavio Monzón García, la más acusada de organizar la masacre de 1978 (Grandin 239-241). La caída de Arbenz liberó a los finqueros locales del peso de las reformas, lo que les permitió usar su recién restaurada autonomía para sus propios intereses.

El trabajo forzado se reactivó y produjo la consecuente caída del salario. Pero, además, en Panzós hubo una situación particular. Buena parte de las propiedades que la reforma agraria fueron nacionalizadas o "quedaron en un estatus legal nebuloso" (Grandin 243), por lo cual, aprovechando esto, los campesinos se trasladaron a esas tierras sin sembrar y fundaron asentamientos. Del otro lado, los finqueros usaban la legislación agraria posterior a 1954 para reclamar esas tierras como propiedad privada. Ya para los sesenta, el nivel de apropiación de tierras dejaba a los campesinos con pocas posibilidades de maniobra y se vieron obligados a trasladarse con frecuencia hacia las riberas de los ríos, aprovechando una ley que declaraba propiedad nacional una extensión de 100 metros a cada lado de cualquier cuerpo de agua. Ante la injusta situación que vivían las familias q'eqchíes de Cahaboncito, Semococh, Rubeltzul, Caguanchá, Sepacay, Finca Mayagua y La Soledad, la adjudicación de tierras para su subsistencia se convirtió en una continua demanda. Pero también ocurrió lo mismo con la impunidad con la que los finqueros ejercían su poder. El Estado, por su parte, "prometía, pero nunca cumplía y la crisis se agravó" (Grandin 250). Este último, en realidad, estaba preocupado por otros asuntos, como, por ejemplo, el de la seguridad, por lo cual aumentó considerablemente el número de militares en toda la zona del Valle. A menos de un mes de la masacre, como antesala, sucedió un nuevo conflicto (no solo por reclamo de tierras, sino de trabajo campesino no remunerado) de mayor magnitud por el grado de acción y unidad de los q'eqchíes y por las respuestas represivas de los militares junto a los propios acusados, la familia Monzón. En este clima de tensión surgió la posterior marcha del 29 de mayo y el apoderamiento de la plaza municipal de Panzós por parte de los campesinos.

Las acusaciones de premeditación y conspiración de la masacre -la creencia común de que Monzón había sobornado al Ejército para que se instalara en la plaza y reprimiera a los manifestantes-y los testimonios de los sobrevivientes a través de la prensa detonaron un conflicto político, en el que la masacre no pudo ser negada por las autoridades. Los q'eqchíes sobrevivientes que viajaron a la capital, en su accionar promovieron la unión de la diversa izquierda urbana que inmediatamente organizó manifestaciones. También impulsaron la participación de sindicatos, partidos políticos y la Iglesia. Según Grandin, por primera vez desde 1954, los manifestantes acusaban públicamente al Estado de asesinato y genocidio: 
JEAN JEAN. M • Muralismo y memorias en América Latina: el caso del mural comunitario y colaborativo sobre la masacre de Panzós en Guatemala

Sindicatos, grupos profesionales y religiosos y asociaciones universitarias -casi

todas las organizaciones sociales existentes publicaron anuncios pagados

denunciando el crimen. La Iglesia Católica (...) emitió su más dura condena al

gobierno hasta entonces, exigiendo una política agraria integral, justa y equitativa.

En el Congreso de la República la masacre fue la chispa que encendió tres meses de

debates y llamados de reforma, incluso de reforma agraria (Grandin 267-8).

Sin embargo, nada de esto último sucedió. Por el contrario, a los bloqueos políticos, les sucedieron actos de violencia como asesinatos a políticos opositores, activistas y referentes sindicalistas y universitarios. Por su parte, el PGT tomó represalias y asesinó a 19 policías militares en la capital. Este hecho dividió y diezmó al partido. En las zonas rurales la violencia continuó y se agravó. Para los sindicalistas la masacre de Panzós significó una "declaración de guerra, después de la cual el Estado inició su limpieza social" (273). Para muchos de los activistas indígenas, Panzós llegó a representar un cambio en las relaciones entre las comunidades indígenas y el gobierno. El fracaso de las reformas, combinado a la represión intensificada, produjo niveles de crisis nunca antes experimentados. En este sentido, para Grandin, la masacre no fue solo una expresión de contradicción entre reforma y reacción, sino que se convirtió en su símbolo a nivel nacional (277).

\section{El mural sobre las memorias de la masacre de Panzós}

Antes de comenzar el análisis del mural que nos convoca, conviene mencionar brevemente algunas apreciaciones sobre el muralismo en América Latina. El muralismo, como movimiento artístico, tiene una rica historia en América Latina en el siglo XX, cuyo punto de partida ha sido la fundación en México, en el año 1922, del Movimiento de Pintura Mural. Durante la primera mitad de este siglo, se dio en varios países latinoamericanos una búsqueda por la independencia artística que tuvo como resultados una vasta producción de propuestas originales y diferentes entre sí. En clave de vanguardias, surgirán renovados movimientos artísticos, como el muralismo, que tratarán la cuestión de lo latinoamericano y la identidad a través de una estrecha vinculación entre el desarrollo de lo político, marcado por el colonialismo, y la necesidad de manifestaciones culturales propias como testimonio de la liberación del tutelaje europeo y como parámetros frente al creciente imperialismo estadounidense. Se trata de la búsqueda de un arte distinto, inspirado en las raíces propias y por ende de las historias, los estilos de vida, la cotidianeidad y objetos propios de los grupos marginados en América Latina: las comunidades indígenas. En el contexto de la Revolución Mexicana (1910-1924), el caso mexicano resultó paradigmático, en tanto que fue el que impulsó el desarrollo del muralismo como movimiento artístico en el resto de Latinoamérica. Un movimiento que perseguía una función social y pedagógica del arte. A partir de 1930, el movimiento muralista mexicano se expandió por otros países como Brasil, Perú y Argentina. En Guatemala, las primeras experiencias de murales después de la Colonia, se dan durante la dictadura del general Jorge Ubico Castañeada (1931-1944). Más adelante, el espíritu revolucionario 
guatemalteco tomaría algunos patrones estéticos ya practicados en otras revoluciones (soviética, mexicana). En las décadas siguientes, surgieron asociaciones, escuelas y grupos de artistas e intelectuales, entre los cuales cabe destacar: la Generación del 40, el Círculo Acento, la Asociación de Profesores y Estudiantes de Belleza Artes (APEBA), la Asociación Guatemaltecas de Escritores y Artistas Revolucionarios (AGEAR), entre otros.

Este breve recorrido por los orígenes del muralismo como movimiento artístico en América Latina nos brinda una idea, no solo de los antecedentes de la práctica mural, sino fundamentalmente de las temáticas, problemáticas y protagonistas que le dieron sus contenidos. A partir de eso, las formas o cualidades estéticas del muralismo cobraron su sentido. Sin embargo, a lo largo del tiempo, esta práctica ha sufrido ciertas modificaciones que tienen que ver con los acontecimientos ya mencionados anteriormente en los primeros apartados. Especialmente, a partir de la década del setenta, los contenidos fueron plasmando en los muros los hechos y consecuencias de masacres, genocidios y terrorismos de Estado. Los muros se convirtieron en soportes para sus denuncias, reclamos de verdad, justicia y especialmente de memoria. En el año 2010, las artistas y docentes Claudia Verenice Flores Escolero, Rosa del Carmen Argueta y Claudia Bernardi de la Escuela de Arte y Taller Abierto de Perquin, El Salvador, fueron convocadas por el ECAP (Equipo de Estudios Comunitarios y Acción Psicosocical) a organizar la realización de un mural comunitario y colaborativo sobre la masacre de Panzós ${ }^{5}$. Anteriormente, esta organización -que provee apoyo psicosocial a sobrevivientes de masacres y a víctimas que han abierto causas judiciales en cortes guatemaltecas o internacionales- las había invitado a diseñar y dirigir proyectos de arte con indígenas sobrevivientes de masacres y víctimas de violencia de Estado en Antigua (2007), en Huehueteango (2008) y en Cobán y Rabinal (2009). A principios del 2010, Carlos Paredes y Jacqueline Mazariaga, psicólogos sociales del ECAP, se reunieron con Ricardo Summler, alcalde de Panzós, para solicitarle la autorización de realizar el mural en el interior del Palacio Municipal. Mural que reuniría a los sobrevivientes de la masacre y otros actores de la comunidad local como maestros, organizadores comunitarios, agencias locales, entre otros. Una vez concedido el permiso, comenzaron los preparativos. De acuerdo con el relato de las artistas, los primeros intercambios de ideas, propuestas y dudas se dieron a través de emails. Esto se correspondía con la necesidad de conocer previamente las condiciones del espacio donde se realizaría el mural y la cantidad de personas con las que se contaría para trabajar. Desde Panzós, les confirmaron que al menos 200 personas habían manifestado la intención de participar. Por otro lado, el mural tendría grandes dimensiones, pues la pared seleccionada medía 15 metros de largo por 4 metros de alto. En el mes de junio, las artistas partieron de El Salvador hacia Panzós. Con ellas viajaban una cuantiosa cantidad de materiales: pintura mural, pinceles, barnices, tizas, baldes plásticos, cubiertas de plástico para el piso, papeles, lápices, etc.

Cuando llegaron, se encontraron con que la gente estaba lista y dispuesta a participar en el proyecto "sin haberse encontrado nunca con las artistas facilitadoras y sin nunca haber hecho un trabajo que involucrase este tipo de arte. Ellos se habían comprometido a estar en este grupo por una semana, quizás por 10 días" (Flores et al. 4). Aquí aparecen dos cosas interesantes. Por un lado, que las artistas destacan la predisposición ante la ausencia de un proceso previo, que antecede todo trabajo comunitario y es el del establecimiento de la confianza mutua, la generación de empatía y que los y las participantes realmente logren sentirse integrados en el proyecto por las artistas y organizadores involucrados. En este sentido, la segunda observación es que las artistas se autoreferencian como artistas facilitadoras, es decir, se corren de un posible posicionamiento

\footnotetext{
${ }^{5}$ Este nuevo proyecto en Panzós fue financiado gracias al aporte de NALAC, National Association of Latino Art and Culture, y a la beca Transnational Cultural Remittances (TCR).
} 
JEAN JEAN. M • Muralismo y memorias en América Latina: el caso del mural comunitario y colaborativo sobre la masacre de Panzós en Guatemala

verticalista que las ubique como las hacedoras del mural, algo que le restaría valor al trabajo de los participantes, quienes en realidad fueron los diseñadores, dibujantes y pintores en la pared. De hecho, en más de una oportunidad ellas aclaran que el mural es de ellos/as, "el Mural de Panzós les pertenece a ellos, a sus comunidades, a la memoria histórica y a la persistente demanda de justicia" (51). Su trabajo como artistas, docentes y organizadoras fue de mediación. Además, hay que mencionar que los y las participantes del proyecto ya conocían el trabajo del ECAP y consideraron que quienes los había asistido para buscar a sus muertos/as era gente en quien se podía confiar: "ahora, ECAP les presentaba la oportunidad de crear un mural colaborativo que contara sus historias personales y comunitarias sobre los desafíos y riesgos que habían sufrido en los últimos 30 años. Asumían que este proyecto se merecía la misma confianza" (6).

El Grupo de Arte y Memoria, como las artistas lo denominaron, estuvo conformado entonces por mujeres, hombres y niños q'eqchíes, sobrevivientes y familiares de las víctimas de la masacre de 1978 y otros miembros jóvenes de la comunidad. Muy pocos/as hablaban español y la mayoría eran analfabetos/as. Así, para facilitar la comunicación, dos intérpretes, Francisco Cuz y Matilde Caal de la comunidad, trabajaron junto a ellos/as en todo momento. El primer encuentro tuvo lugar al aire libre, en El Estor, a orillas del Lago Izabal, a una hora al Noreste de Panzós. Se acercaron 75 q'eqchíes, muchos/as de comunidades lejanas.

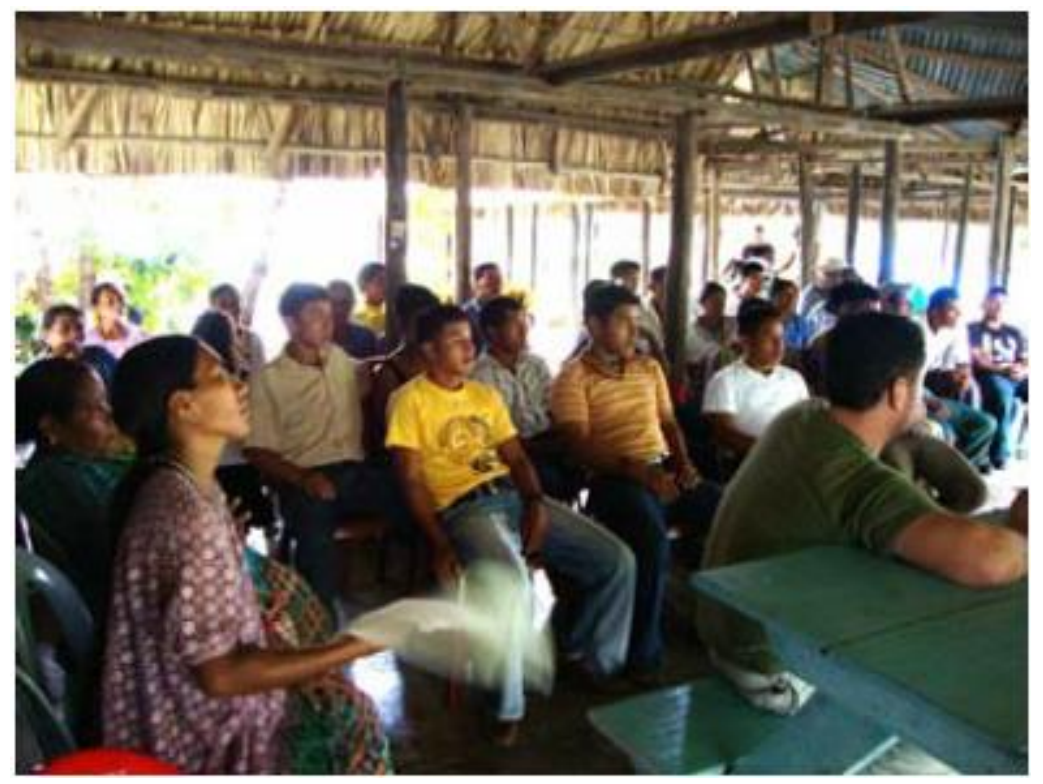

Imagen 1. Participantes del proyecto durante los primeros encuentros.. Fuente: Flores et al. $2010^{6}$.

Las artistas mostraron los trabajos anteriormente realizados de la Escuela de Arte y Taller Abierto de Perquin, desde su creación en 2005: murales, intervenciones urbanas, y clases de arte llevados a cabo en El Salvador, Guatemala y Colombia. Un hecho significativo de este momento fue que a los/as presentes les llamó mucho la atención el mural colaborativo y comunitario creado en el año 2006 en El Mozote, conmemorando los 25 años de la masacre. En ese mismo lugar donde había acaecido la muerte de más de 1000 personas, se erigía ahora un mural que contaba la historia

${ }^{6}$ Las imágenes corresponden a Flores et al. (2010) 
de El Mozote antes de la guerra civil, cuando la violencia no había destruido aún esa pequeña comunidad del Norte de El Salvador. A continuación, las artistas preguntaron si podría haber otra guerra en Guatemala:

La respuesta fue demoledora. Los jóvenes dijeron que otro conflicto armado podría suceder en Guatemala porque la pobreza y la segregación que siempre había sufrido la población indígena nunca se habían remediado. La tierra que los pueblos indígenas demandaron en 1978 todavía pertenecía a los finqueros (terratenientes). Gente extranjera había llegado a sus tierras apropiándose de ellas y nunca más devolvieron lo que habían robado. Una reforma agraria nunca ocurrió. La gente confronta hoy, las mismas dificultades que sus ancestros tenían que enfrentar al reclamar las tierras, un siglo atrás (Flores et al. 7).

A partir del segundo día, reunidos/as en el mismo lugar, los/as participantes ya tomaron hojas y lápices para comenzar a dibujar. Lo hicieron en grupos de 8 o 10 personas. Las artistas guiaron con las siguientes preguntas: ¿Qué les gustaría decir? ¿De qué hablará este mural? ¿Qué historia contará? ¿Hay algún hecho en particular o relatos personales o comunitarios que quisieran compartir en este mural para que otra gente los conozca? ¿Quisieran decir en este mural algo que nunca antes habían dicho, que nunca habían compartido con nadie? Los dibujos mostraron montañas, animales, pájaros, árboles, plantaciones de maíz y de cardamomo, casas, algunas incendiadas, otras destruidas. También el Río Polochic, el puente, gente cruzado el puente, gente muerta arrojada al río. Algunos de los/as jóvenes que habían trabajado con las personas de mayor edad mostraban dibujos referentes a violencia detallada. Muchas de las mujeres dibujaron retratos de sus hijos e hijas muertos/as. Más aún, las madres habían identificado los lugares precisos donde sus hijos habían muerto. Y ellas mismas aparecían representadas buscándolos.

Ya el 30 de junio, la cita tuvo lugar en el Palacio Municipal. Comenzaba el traspaso de los bocetos a la pared. En esos primeros momentos todavía había discusiones sobre qué representar y cómo hacerlo. Todo se compartía y consensuaba colectivamente. Finalmente, los/as participantes comenzaron a dibujar las ideas principales teniendo en consideración una línea temática y temporal que transitaba desde el pasado hasta un futuro posible. Algunas de estas ideas fueron:

La vida en Alta Verapaz antes de que la tierra se les fuera usurpada y negada; la "razón” de la violencia desatada; el éxodo de las comunidades civiles indígenas a las montañas; el impacto de la represión causada por el ejército de Guatemalo; la masacre; mirando hacia el futuro (Flores et al. 18). 
JEAN JEAN. M • Muralismo y memorias en América Latina: el caso del mural comunitario y colaborativo sobre la masacre de Panzós en Guatemala

Según las artistas, el paso del dibujo a la pintura fue rápido y sin inseguridades. Solo les sugirieron que tuvieran en cuenta la ubicación de la línea del horizonte que divide el plano del cielo con el de la tierra y les recomendaron recordar que, en un mural, aquello que está más lejos, se pinta siempre primero. Así fue como comenzaron a pintar el paisaje y luego las personas, los detalles y elementos narrativos que se verían de cerca.

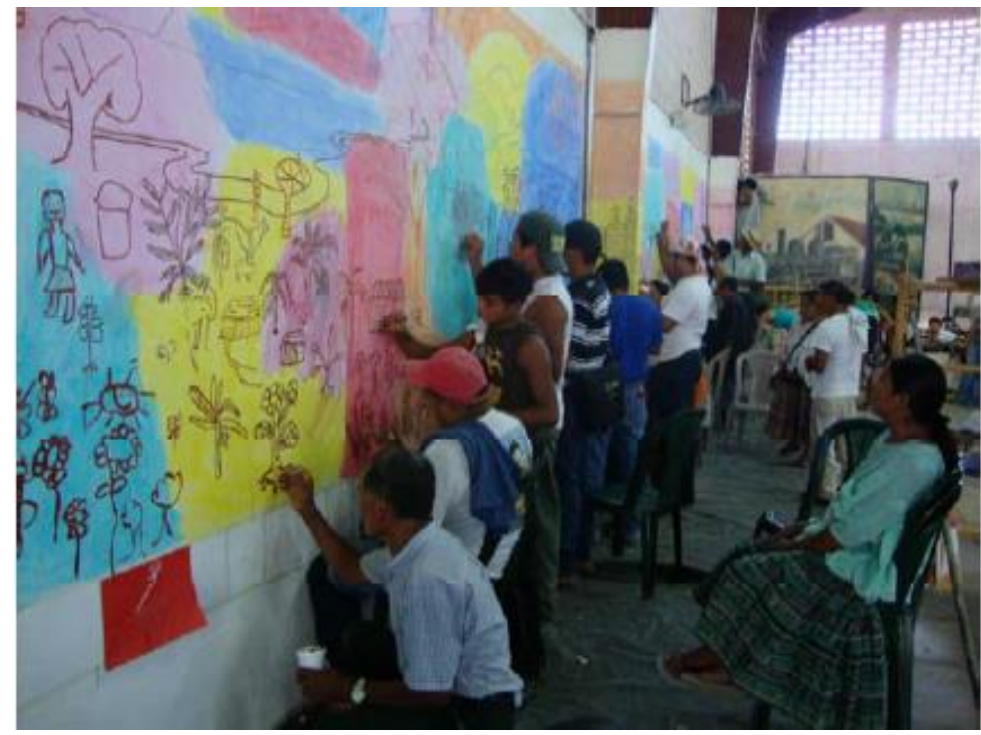

Imagen 2. Participantes dibujando sobre la pared que previamente fue segmentada a través de colores como una estrategia para orientar visualmente mejor a los/as hacedores/as. Los colores por segmentos le quitan fuerza a la inmensidad que aparenta la totalidad de la pared en color blanco.

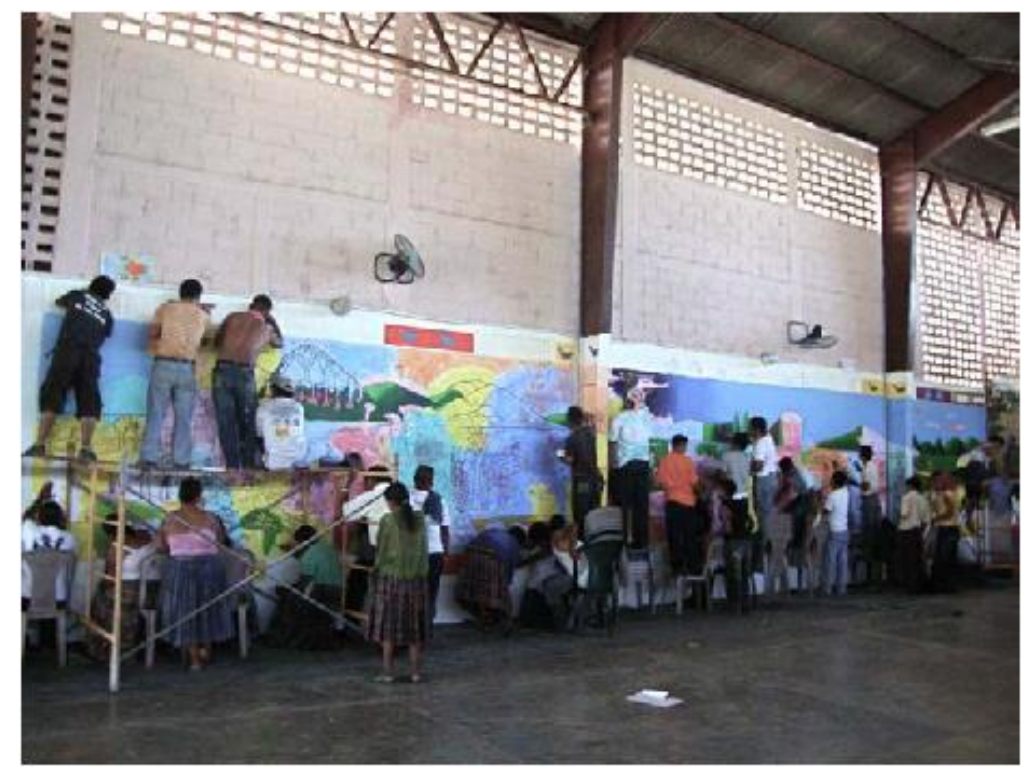


Imagen 3. Una vista más panorámica que da cuenta no solo de la magnitud del soporte y el mural, sino de todas las personas que trabajaron simultáneamente.



Imagen 4. Del dibujo a la pintura.

En cinco días continuos de trabajo dentro del Palacio, el mural estuvo terminado. La lectura de esta narrativa plástico visual tiene una dirección de este a oeste y podría ser leída en tres momentos. Un primer y segundo panel, como alusión al pasado, a la vida antes de la masacre, nos muestra el Río Polochic lleno de vida, de barcos y cayucos (canoas hechas de troncos de árbol), de peces y otras especies típicas de la ribera. Entre el río y las vías del tren, aparecen casas, personas, animales y plantaciones de maíz que recuerdan cuando la vida era limitada, pero la gente todavía tenía un pedazo de tierra para sembrar y vivir (Imagen 5). Hacia el segundo panel, se puede observar la división de tierras realizada por los finqueros y sus propiedades privadas enmarcadas con alambres de púas y cercos. A su alrededor, en lugar de plantaciones de maíz, representaron el ganado que, si bien siempre hubo en la región, los finqueros habían extendido esta práctica en perjuicio de la actividad de los campesinos. El segundo momento está limitado a su derecha por el Río Boca Nueva que atraviesa perpendicularmente el paisaje. A continuación, se relata detalladamente la masacre. En el centro de la escena, aparece la plaza en donde yacen las personas que allí murieron asesinadas a manos de los solados, que fueron representados con sus armas y vestimenta típica (Imagen 6). Hacia la derecha vemos casas incendiadas y personas tratando de huir de la persecución de los militares, algunos alcanzados por las balas de estos. El Ejército también está representado mediante camiones y los helicópteros que sobrevuelan las montañas. Allí, un hombre y su hijo acechados por un ave de rapiña simbolizan la muerte de aquellos asesinados en la huida hacia las montañas y también durante su escondite en ese hostil lugar (Imagen 7). 
JEAN JEAN. M • Muralismo y memorias en América Latina: el caso del mural comunitario y colaborativo sobre la masacre de Panzós en Guatemala

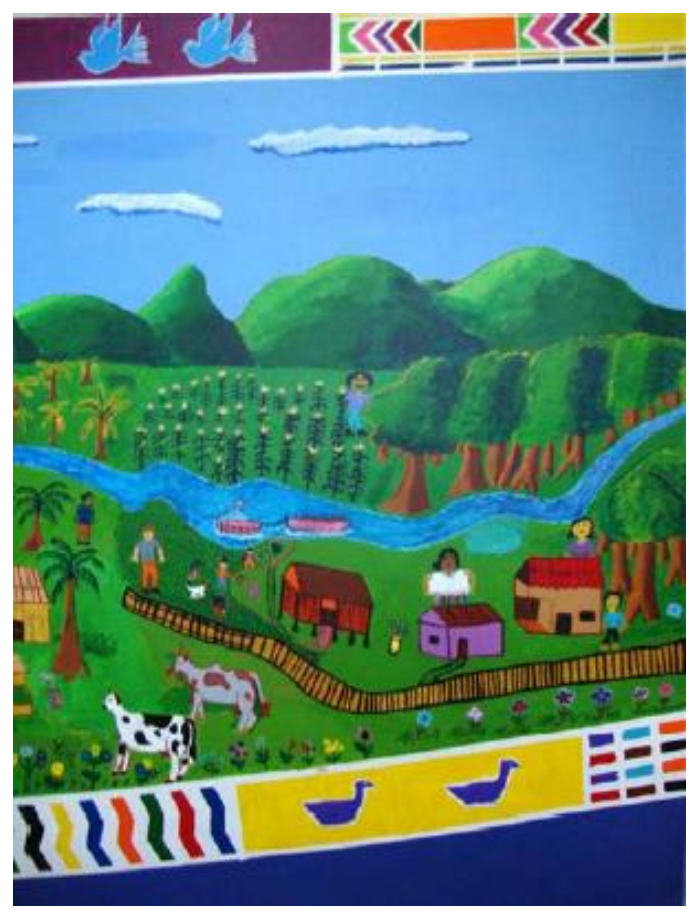

Imagen 5. La vida antes de la masacre.

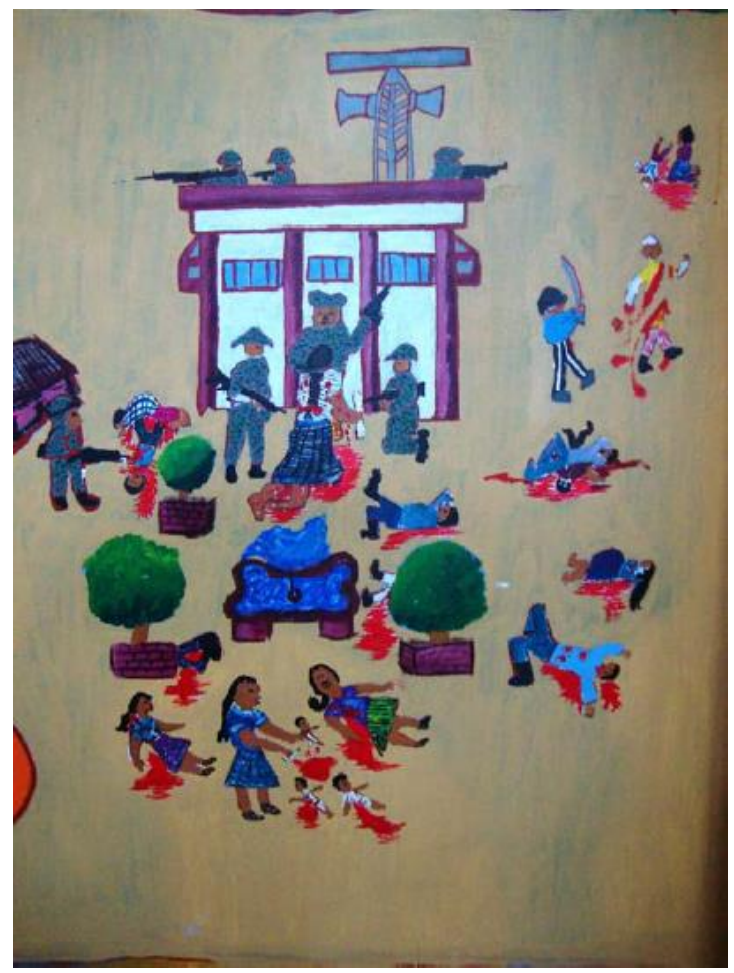

Imagen 6. La masacre en la plaza. 


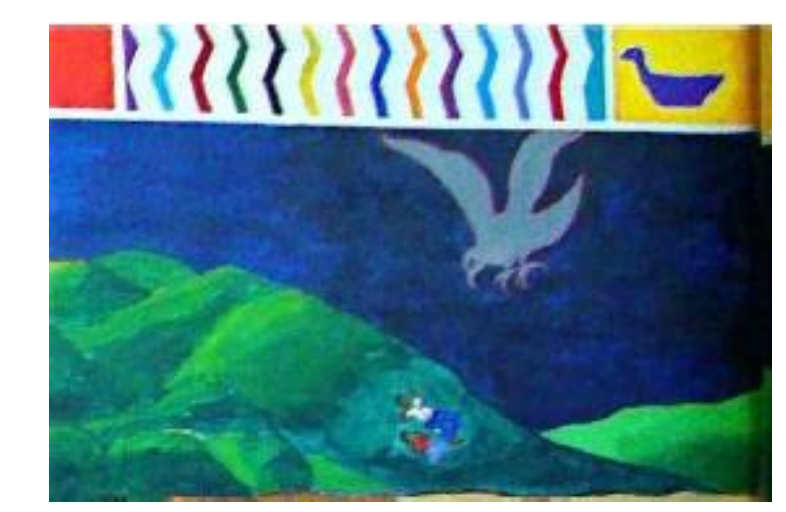

Imagen 7. Detalle, asesinatos en la huida hacia las montañas.

Resulta interesante destacar el uso de las columnas que por decisión colectiva fueron incluidas en el mural. Es así como, por ejemplo, sus lados fueron destinados a relatar detalles como la dura vida en las montañas de los sobrevivientes y también el entierro de los/as muertos/as frente a la Iglesia de Panzós (Imagen 8). El paso al tercer momento resulta muy significativo. Hacia la izquierda de los camiones militares, se abre hasta las montañas un arcoíris que emerge de un altar maya, donde hay velas prendidas junto al copal sagrado, el incienso de los dioses. A su lado, aparece la figura humana de mayores dimensiones del mural. Se trata de Adelina Caal, conocida como "Mamá Maquín”, líder del movimiento y la marcha, quien fuera la primera asesinada de la masacre según los testimonios de los sobrevivientes. Mirándonos fijamente, está vestida con el traje típico de Alta Verapaz, con su brazo izquierdo sostiene una canasta con cuatro elotes, cada uno de diferente color:

El Rojo, representa el nacimiento del día, el naciente. Amarillo es el Viento. Blanco

es el agua y Negro es el fin del día, el poniente. El centro pivotal de la Verdad de la cosmogonía Maya se encuentra en estos cuatro colores y su significado: vida, muerte, transición y supervivencia (Flores et al. 39).

En su mano derecha, "Mamá Maquín” sostiene el documento que demandaba los derechos a la tenencia de propiedad de sus tierras y que sería entregado al entonces alcalde de Panzós (Imagen 9). Según los sobrevivientes, a pesar de ser baleada y asesinada, nunca dejó de sostener el documento que portaba. La propuesta de este tipo de representación, en la que "Mamá Maquín" aparece viva en el presente y no muerta, fue de su nieta María Maquín, quien el día de la masacre, con 12 años de edad, se encontraba junto a su abuela y sobrevivió tras hacerse la muerta y escapar hacia las montañas. Esto simboliza la pervivencia de la lucha por los derechos de los y las q'eqchíes que encabezó esta mujer, que además se convirtió en un ícono de su género y del rol de las mujeres ante los conflictos y resistencias que esta comunidad tuvo que enfrentar. Finalmente, luego de esta imponente figura, llega la visión del futuro posible. Allí los/as participantes dibujaron y pintaron sus deseos. Reaparece la naturaleza en todo su esplendor rodeando al río Polochic que termina su recorrido al oeste. Una escuela con la bandera de Guatemala congrega la presencia de niños y niñas que juegan sonrientes sobre el verde pasto. También aparece el edificio de tres pisos del Palacio Municipal y las exhumaciones realizadas en 1997. Por otro lado, fueron representadas dos mujeres 
JEAN JEAN. M • Muralismo y memorias en América Latina: el caso del mural comunitario y colaborativo sobre la masacre de Panzós en Guatemala

tomadas de la mano, una indígena, la otra ladina (Imagen 10). De acuerdo con Matilde Caal, quien las pintó, esto simboliza la unión que debe haber entre la gente indígena y la no indígena para demandar juntos justicia y responsabilidad para impedir que suceda otra masacre como la de Panzós (Flores Escolero et al. 40). Hacia el final, una mujer y una niña de espaldas miran hacia el horizonte, hacia el atardecer. La niña sostiene al sol como si este fuera un barrilete en movimiento (Imagen 11). Las artistas sugieren "la niña mira confiada hacia un paisaje brillante y pacífico. La niña puede ver el futuro. El futuro, pareciera, está ahora en sus manos." (42). Finalmente, no queremos dejar de mencionar que todo el límite del mural fue bordeado con una guarda como elemento decorativo, realizada con motivos típicos de las vestimentas de las mujeres guatemaltecas como los huipiles (blusa) y en los cortes (falda) (Imagen 12).

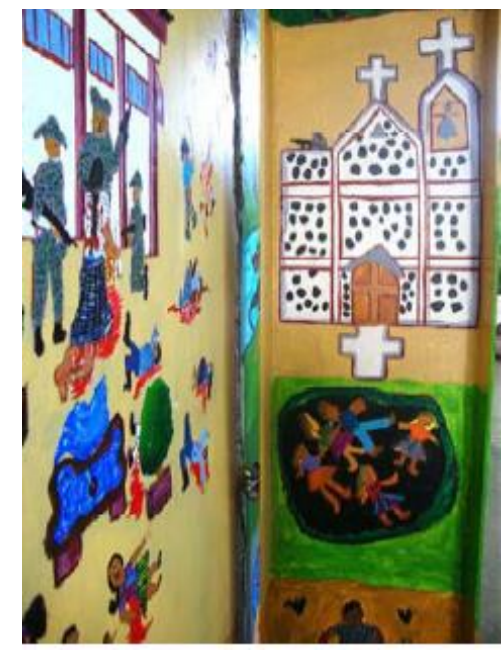

Imagen 8. Detalle del uso de las columnas.

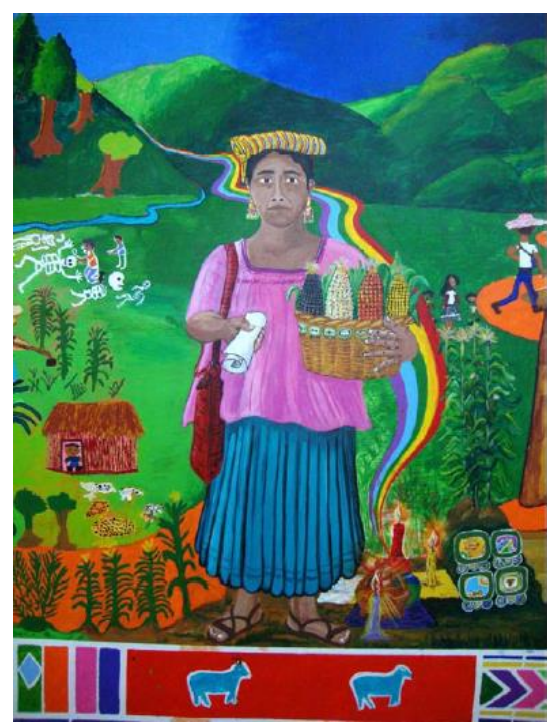

Imagen 9. Representación de "Mamá Maquín". 


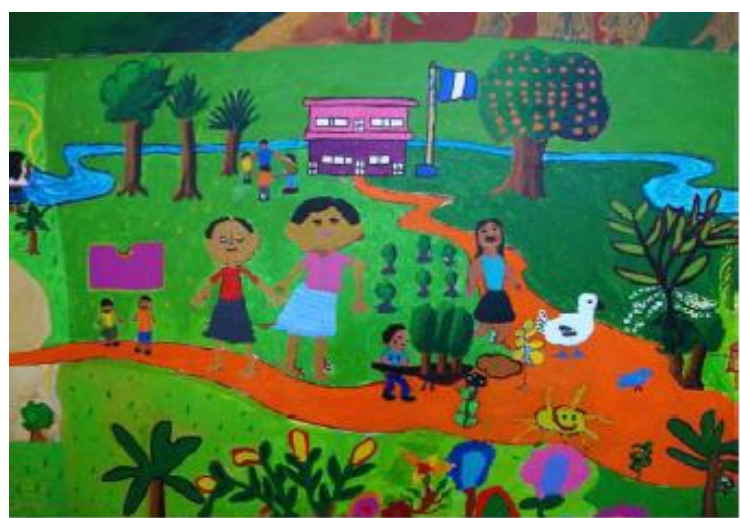

Imagen 10. La naturaleza. La Escuela. Niñas y niños jugando. Representaciones de mujer indígena y mujer ladina tomadas de la mano.

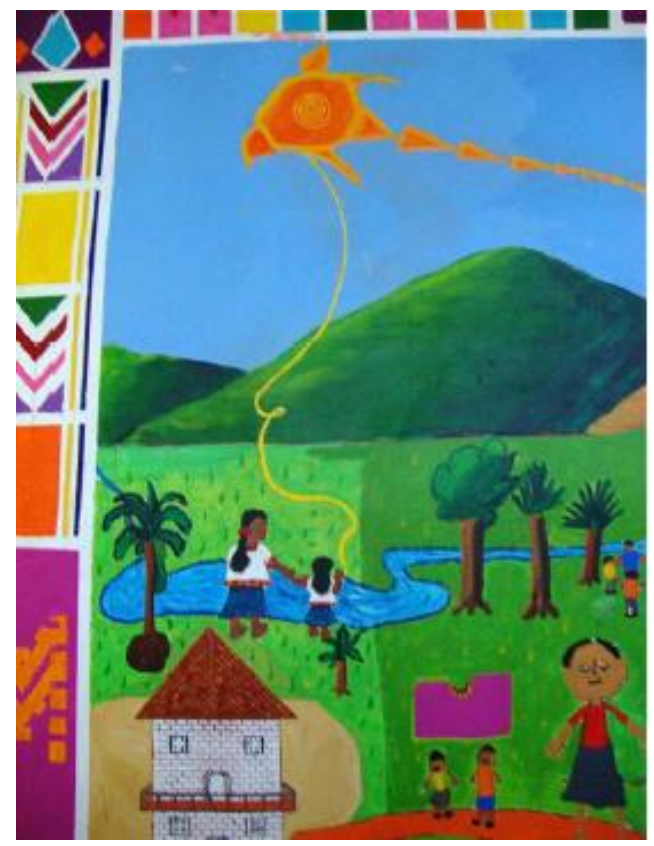

Imagen 11. Mujer y niña, que remonta al sol como un barrilete, tomadas de la mano miran hacia el horizonte, metáfora del futuro esperanzador de la comunidad.



Imagen 12. Panorámica del mural. Guarda que bordea el límite del relato visual. 
JEAN JEAN. M • Muralismo y memorias en América Latina: el caso del mural comunitario y colaborativo sobre la masacre de Panzós en Guatemala

\section{Reflexiones finales: la práctica artística vinculada a los procesos de memorias de hechos traumáticos del pasado reciente}

La construcción de la obra artística de Panzós en Guatemala, se inscribe en los diversos modos en que el pasado de espiral de violencia -masacres, genocidios y terrorismos de Estado- se han presentado en el siglo XX en América Latina. El objetivo de este artículo identificó la construcción del "Mural de la masacre de Panzós" como una práctica artística vinculada a los procesos de memorias. El desarrollo de este mural significó un proceso social por la memoria, en el que diferentes actores despliegan estrategias de "hacer memoria" diversas. Estos emprendedores de memoria asumen el rol activo de promover la transmisión de esa memoria a la comunidad presente y a las generaciones futuras. En el caso del mural de Panzós, podría decirse que los emprendedores fueron los y las organizadores/as del proyecto, en tanto que a partir de sus acciones surgió el espacio de convocatoria para que sobrevivientes, familiares y demás integrantes de la comunidad maya-q'eqchí tuvieran la posibilidad de trabajar sobre sus memorias a través de una manifestación artística. Esto no es un detalle menor, ya que uno de los reclamos actuales de esta comunidad es la de tener visibilidad y escucha. Tampoco lo es que el mural haya sido pintado en el interior de una institución gubernamental, nada más ni nada menos que en el Palacio Municipal, a metros de donde ocurrió la masacre. Esta práctica artística allí realizada mantiene una cualidad de denuncia frente al olvido o al silencio, pretendiendo incidir, no solo en el recuerdo de los hechos o hasta un posible homenaje, sino sobre todo en las condiciones sociopolíticas actuales de la comunidad. El mural es un gesto político que surge sobre un pasado, pero se orienta desde el presente y para el futuro. Las narraciones visuales del mural refuerzan las memorias de la masacre, disputan sus sentidos e interpelan al Estado, que, desde aquel momento, intentó instalar versiones del acontecimiento que distan considerablemente de lo testimoniado por las y los sobrevivientes. Además, ninguno de los responsables de la masacre ha sido juzgado.

No podremos en este trabajo tener mayores certezas en cuanto a los significados de la experiencia en sus hacedores, más aún sobre lo que haya sucedido en la posteridad, pues nos hemos basado en el relato construido de la experiencia de las artistas y docentes que facilitaron la creación del mural. Sin embargo, podemos atrevernos a decir que probablemente no el mural en sí, sino su proceso de construcción desde el día uno -en aquella primera reunión de presentación del proyecto- ha sido de alguna manera reparador para los y las participantes. Nos anima a arriesgar esta hipótesis el propio lugar del arte para trabajar las memorias de este tipo de hechos y las posibilidades que habilita (Jean Jean 128). ¿Por qué el arte para construir memorias? ¿Por qué el arte para narrar hechos de violencia extrema y consecuencias que pueden considerarse traumáticas? ¿Por qué el muralismo? A menudo se considera que el arte funciona como un vehículo para las memorias que permiten articular el pasado traumático con el presente desde dispositivos lúdicos y reflexivos. En este sentido, el arte ha mantenido un lugar muy cercano y privilegiado como mediador en la elaboración de este tipo de experiencias, en tanto sus lenguajes y la especificidad de sus materialidades y procedimientos pueden eludir la exigencia de racionalidad de los textos epistémicos, redimensionar la transferencia de mensajes, y hasta impulsar el acercamiento al pasado traumático (133). Con esto queremos decir que el arte permite otro tipo de posibilidades que se alejan de las disciplinas tradicionales, en las que por causa de rigorismo o la exigencia de poner en palabras aquello que resulta difícil de ser dicho, pueden no ser eficaces para la elaboración del acontecimiento por parte de las víctimas. Siguiendo a LaCapra, en esto vemos la posibilidad de que una manifestación artística "pueda ser leída como una perspectiva significativa y crítica de la 
relación de una comunidad con su pasado en términos de la memoria del trauma colectivo e individual, con la posibilidad de que el arte, en sus específicas (...) formas de testimoniar o ser testigo de ese pasado, contribuya a elaborar y superar ese pasado" (67). El día de la inauguración del mural, en el que se entregó un diploma de reconocimiento por el trabajo realizado a sus creadores/as, dicen las artistas:

Muchos de los participantes se acercaban a recibir el diploma llorando. Hombres y

mujeres, muy conmovidos, nos decían que ellos al ser analfabetos, nunca se habían

imaginado, nunca habían soñado con un reconocimiento como este. Estaban

acostumbrados a pensar que ellos no valían, que eran "descartables”. Se les había

negado "un lugar en el mundo" donde se respetara su identidad y su integridad

(Flores et al. 47).

El estudio de la historia reciente nos conduce a indagar sobre los procesos de memorias que surgen desde el presente en comunidades o sociedades que se han visto afectadas por hechos violentos de características o alcances traumáticos no resueltos o no reparados. La memoria colectiva, en tanto proceso social de reconstrucción creativa, emerge como producto de interacciones múltiples de las memorias compartidas, en marcos sociales de referencia y en situación de disputas por el poder. ¿Qué sucede con la memoria colectiva de hechos traumáticos acontecidos en el pasado reciente de una comunidad? La memoria, el recuerdo, la conmemoración, el olvido o los silencios se tornan cruciales cuando se vinculan a experiencias trágicas y traumáticas colectivas de represión y aniquilación. La memoria y el olvido, en estos casos, cobran una significación especial como mecanismo cultural para fortalecer el sentido de pertenencia. Elizabeth Jelin afirma que "las exclusiones, los silencios y las inclusiones a las que se refieren hacen a la reconstrucción de comunidades que fueron fuertemente fracturadas y fragmentadas" (223). Las luchas por la memoria, por los sentidos de ese pasado reciente en el presente, se convierten en luchas políticas. Finalmente, la práctica artística no solo trata de abordar el tema de la representación de episodios traumáticos en clave artística, sino pensar cómo el arte puede colaborar con los procesos de elaboración de las experiencias traumáticas mismas. La práctica mural permitió el trabajo colectivo y colaborativo. Un gesto artístico-político de activación de la memoria colectiva de una comunidad, la de los campesinos mayas q'eqchíes, en la que cualquiera de sus integrantes, pudo convertirse en artista de sus propias memorias y en los y las protagonistas directos de la elaboración de su historia.

\section{Bibliografía}

Calderón, Fernando. Memoria de un olvido. El muralismo boliviano. Nueva Sociedad 116 (1991): 146-152. Impreso. 
JEAN JEAN. M • Muralismo y memorias en América Latina: el caso del mural comunitario y colaborativo sobre la masacre de Panzós en Guatemala

Comunidades de Población en Resistencia. "Panzós Una historia de Despojo: a 35 años de la Masacre.”, 28 de mayo 2013, http://cpr-urbana.blogspot.com.ar/2013/05/panzos-unahistoria-de-despojo-35-ano.

Eder, Rita. "Muralismo mexicano: modernidad e identidad cultural”. A. M. Moraes Belluzzo (Org.) Modernidade: vanguardas artísticas na América Latina. São Paulo: Memorial UNESP, 1990. Impreso.

Eder, Rita. Arte e identidad en América Latina, Oaxaca, 1996. Impreso.

Flores Escolero, Claudia, Rosa del Carmen y Claudia, Bernardi. TZUULTAQ'A Tierra y Valle, Alto y Bajo, Mujer y Hombre. Bueno y Malo. Los Opuestos que Sostienen el Universo. Escuela de Arte y Taller Abierto de Perquin, El Salvador, 2010, http://www.wallsofhope.org/english-tzuultaqa-earth-and-valley-high-and-low-womanand-man-good-and-evil-the-opposites-that-hold-the-universe/

Morales de la Roca, Verali. Manual para la elaboración de murales didácticos en la enseñanza de Historia del Arte. Universidad de San Carlos de Guatemala. Facultad de Arquitectura, 1998. Impreso.

Grandin, Greg. Panzós: la última masacre colonial. América Latina en la Guerra Fría. Guatemala: AVANCSO, 2007. Impreso.

Halperín Donghi, Tulio. Historia contemporánea de América Latina. Buenos Aires: Alianza Editorial, 2005. Impreso.

Hobsbawm, Eric. Historia del siglo XX. Barcelona: Crítica, 1995. Impreso.

Jean Jean, Melina. "Los alcances del arte en la elaboración de acontecimientos traumáticos. Una mirada desde los estudios de memoria". Cuaderno 92. Centro de Estudios en Diseño y Comunicación, Universidad de Palermo. 2019, 127-143. Impreso y digital. https://fido.palermo.edu/servicios_dyc/publicacionesdc/cuadernos/detalle_articulo.php?id _libro=776\&id_articulo $=16188$

Jelin, Elizabeth. "Exclusión, memorias y luchas políticas”. Daniel Mato (Comp.) Cultura, política y sociedad Perspectivas latinoamericanas. Buenos Aires: CLACSO, Consejo Latinoamericano de Ciencias Sociales, 2015. Impreso.

LaCapra, Dominik. Historia en tránsito. Experiencia, identidad, teoría crítica. Buenos Aires: Fondo de Cultura Económica, 2006. Impreso.

Rostica, Julieta. “Guatemala: genocidio, proceso de paz y relaciones étnicas”. Feierstein, D. \& Levy, G. (comps.) Hasta que la muerte nos separe. Poder y Prácticas Sociales Genocidas en América Latina. La Plata: Ediciones Al Margen, 2004. Impreso.

Rousso, Henry. "Desarrollos de la historiografía de la memoria". Aletheia 16. 2018. Digital. http://www.aletheia.fahce.unlp.edu.ar/numeros/numero-

16/conferencia/Conferencia\%20Henry\%20Rousso.doc.pdf

Sanford, Victoria. La Masacre de Panzós: Etnicidad, Tierra y Violencia en Guatemala. Guatemala: F\&G Editores, 2010. Impreso.

Recibido: 10 de junio de 2020 .

Aceptado: 7 de julio de 2020. 